\title{
Trabalhonecessário
}

Issn: 1808 - 799X

ano 14, número $23-2016$

\section{A PRODUÇÃO CIENTÍFICA DO PROFESSOR PESQUISADOR JOVEM-DOUTOR}

\author{
Luciana Rodrigues Ferreira ${ }^{1}$ \\ João dos Reis Silva Júnior²
}

\section{Resumo:}

O artigo apresenta, de forma sintética, o estudo de tese sobre o 'trabalho de professores jovens doutores', analisado a partir do discurso sobre as práticas cotidianas na universidade e a produção de conhecimento. A empiria sobre o trabalho de professores permanentes da pós-graduação, com bolsa produtividade em Pesquisa e com menos de dez anos de doutoramento, no contexto de trabalho na Universidade Federal de São Carlos, SP. O processo de investigação se constituiu de três momentos interligados: estudo teórico e análise documental; coleta de dados, em bases estatísticas oficiais e Currículo Lattes dos professores; e trabalho empírico. Concentrou-se, ao final, no exercício de reflexão acerca de duas dimensões contraditórias reveladas no discurso dos professores: a paixão pelo trabalho docente e a pressão e estranhamento por ele causados. Constatouse que, no contexto de uma cooperação internacional, como estratégia para promover a formação de quadros de pesquisadores nas universidades e a alta produção de conhecimento se tornaram metas nas regulações de agências de fomento, claramente pautadas na velocidade necessária para acompanhar as

\footnotetext{
1 Doutora em Educação, na linha de Estado, Política e Formação Humana, pela Universidade Federal de São Carlos (UFSCar). Bolsista de Pós-Doutorado PNPD/CAPES pelo Programa de Pós-Graduação em Educação da Universidade Federal do Pará. Docente da Universidade da Amazônia (UNAMA). E-mail: lucianarofer@gmail.com.

2 Professor Livre-Docente em Educação pela Faculdade de Educação da Universidade de São Paulo (FE-USP), Doutor em História e Filosofia da Educação pela Pontifícia Universidade Católica de São Paulo com Pós-Doutoramento em Sociologia pela Universidade de Campinas (Unicamp) e, em Economia, pela Faculdade de Economia e Administração da USP (FEA-USP). Professor e pesquisador da Universidade Federal de São Carlos (UFSCar). Visiting Professor na Arizona State University (2014-2015). Pesquisador do CNPq. E-mail: joaodosreissilvajr@gmail.com.
} 


\title{
Trabalhonecessário
}

Issn: 1808 - 799X

ano 14, número $23-2016$

mudanças tecnológicas mundiais, pelas quais o Brasil teria que, num enorme esforço, avançar, criando capacidades e competências em áreas estratégicas, por meio de pesquisas e pesquisadores, especialmente pelos jovens-doutores no âmbito da pós-graduação.

Palavras-Chave: Jovem-Doutor; Trabalho Docente; Políticas Educacionais; Pesquisa; Produção de Conhecimento.

\begin{abstract}
The article presents, in summary form, the thesis on the 'work of doctors young teachers', viewed from the discourse on daily practices at the university and the production of knowledge. The empirical study on the work of permanent teachers graduate with productivity scholarship in research and under ten years of doctoral work in the context of the Federal University of São Carlos, Brazil. The research process consisted of three interconnected moments: theoretical study and document analysis; data collection on official statistics bases and Lattes teachers; and empirical work. Concentrated at the end, in the exercise of reflection about two contradictory dimensions revealed in teachers' discourse: the passion for teaching work and pressure and estrangement caused by it. It was found that in the context of international cooperation, as a strategy to promote the training of staff of researchers in universities and high production of knowledge have become targets in development agencies regulations, clearly guided by the speed needed to keep up with technological changes world, in which Brazil would have it, a huge effort, forward, building capacity and skills in strategic areas, through research and researchers, especially the young-doctors in post-graduate courses.
\end{abstract}

Key-Words: Young-doctor; Teaching Work; Educational Politics; Research; Knowledge Production.

\section{Introdução}

Este artigo é resultado do estudo de tese intitulada " $O$ trabalho do Professor jovem-doutor na pós-graduação: produção de conhecimento e discurso do professor", que teve, como pano de fundo, questões sobre o trabalho docente na universidade pública. Vale ressaltar que este campo apresenta estudos 


\section{Trabalhonecessário}

Issn: 1808 - 799X

ano 14, número $23-2016$

extensos, desde pesquisas em redes integradas ${ }^{3}$, a teses ${ }^{4}$ e dissertações ${ }^{5}$ voltadas para temas como: intensificação do trabalho docente, precarização das relações de trabalho, identidade social, saúde docente, produção de conhecimento, internacionalização, entre outros, que, no âmbito das políticas educacionais, revelam a complexidade das condições de trabalho e os significados deste trabalho para o próprio sujeito.

Destaca-se, nos estudos citados, uma nova realização no plano institucional das universidades públicas, principalmente, a partir de meados dos anos de 1990 e início dos 2000, nos quais o cotidiano da universidade produziu elementos concretos da objetivação das reformas ocorridas no Estado. Ao tempo em que Grupos passam a estudar o trabalho docente e debater a respeito dele, o fazem, como o Grupo de Economia Política e Formação Humana (GEPEFH/UFSCar), o qual investiga a "cultura da universidade pública brasileira, o trabalho dos produtores desta instituição e sua contribuição para a formação humana". (GEPEFH, 2013, p.1)

Avançada nas análises sobre a realidade posta, colocou-se como meta entender a objetivação dessas formulações no Estado, na universidade pública e no trabalho do professor. A pesquisa, iniciada em $2006^{6}$, "[...] buscava, na objetivação das políticas para a universidade pública, responder às indagações sobre a mudança da cultura da universidade pública e do trabalho do professor

\footnotetext{
${ }^{3}$ Neste sentido, destaca-se a articulação nacional da Rede Universitas/Br, vinculada ao Grupo de Trabalho de Políticas da Educação Superior (GT-11/ANPEd), como: Sguissardi e Silva Júnior (2009); Mancebo (2004; 2010; 2013); Lima (2011); Silva Júnior (2011) e; Mancebo e Silva Júnior (2012).

${ }^{4}$ Cf.: Lemos (2005; Lancillotti (2008); Guimarães (2014).

${ }^{5}$ Cf.: Silva (2005); Vicentini (2006); Dantas (2006); Sagrillo (2009).

6 Trata-se da Pesquisa sob o título: Mercantilização da Esfera Pública e Universidade Nova Identidade Universitária e Trabalho Docente das IFES da região Sudeste, financiada pela FAPESP (Processo n. 2004/07559-4), realizada no período de 2006 a 2008, coordenada pelo Professor Valdemar Sguissardi.
} 


\section{Trabalhonecessário}

Issn: 1808 - 799X

ano 14, número $23-2016$

desta instituição", tendo como resultado o livro Trabalho Intensificado nas Federais - pós-graduação e produtivismo acadêmico (SGUISSARDI; SILVA JÚNIOR, 2009), já na 3ª reimpressão (2011).

Sguissardi e Silva Júnior (2009) fazem, no estudo citado, o neologismo "produtivismo acadêmico" ter todo o sentido na compreensão do cotidiano, o qual:

[...] consiste em produzir a materialidade institucional para o que se chama produtivismo acadêmico em suas múltiplas formas de concretização: da produção de muitos artigos, capítulos de livros e livros, mas de forma mais acentuada na relação direta com o mercado. Esta ideologia do produtivismo acadêmico origina-se do Estado, com mediação da CAPES e do CNPq, acrescidos da FINEP e do BNDES, entre outros. O produtivismo acadêmico assume sua forma mais acabada e objetivada no Currículo Lattes (CV-Lattes). O Currículo Lattes consiste no porttólio de muitos doutores, formados depois de implantado o novo Modelo CAPES de Avaliação, em 1996-1997, a correrem atrás de pósdoutoramentos, de publicações, de bolsas de produtividade, de participação em congressos bem classificados academicamente, isto no objetivo de fazer caminhar a "nova universidade", sem saberem bem para onde ela caminha. (SGUISSARDI, SILVA JÚNIOR, 2009, p. 45).

Nesta percepção, observa-se o professor universitário concursado para o exercício da docência, pesquisa e extensão, "[...] compelido à complementação salarial e à ideologia" produtivista, a qual se coloca como "um dos pilares centrais da cultura da instituição universitária." (SGUISSARDI, SILVA JÚNIOR, 2009, p. 44). Os autores afirmam que o trabalho do professor converteu-se em sua droga cotidiana, sua paixão. "Muitos trabalhos ou "obrigações" de ofício, [são] tomados messianicamente como missão" (idem).

Agregado à empiria demonstrada nos estudos citados e às questões em debate sobre o trabalho do professor, tem-se o segundo movimento, que acontece em decorrência das políticas educacionais que visam a mudanças 


\section{Trabalhonecessário}

Issn: 1808 - 799X

ano 14, número $23-2016$

estruturais na própria universidade e podem alterar toda cultura na produção de conhecimento e na relação do professor com seu trabalho. Desta análise, emerge a seguinte questão: o que dizem os professores jovens-doutores da UFSCar, com bolsa Produtividade em Pesquisa e com vínculo em Programas de PósGraduação, acerca de seu trabalho e da produção de conhecimento? A partir das falas e dos dados, pode-se elaborar um perfil sobre o trabalho destes professores pesquisadores em relação à atual conjuntura do trabalho na pós-graduação, com a expansão, a regulação e o financiamento de pesquisas?

A estes recém-doutores denominou-se de professores jovens-doutores, para referenciar aqueles que se titularam e seguiram a carreira de docente pesquisador na última década, justamente, marcada pelo processo de mudança da pós-graduação, a qual consolida um novo processo de avaliação dos Programas de Pós-Graduação, em 1998, quando são iniciados períodos trienais de avaliação (1998-2000; 2001-2003; 2004-2006; 2007-2009; 2010-2012). Por entender que toda política necessita de um processo de implementação e maturação de um novo ordenamento, 2004 marca o início do terceiro triênio de avaliação, tempo em que todos os Programas se ajustariam, em tese, às novas regras de produção e de coleta de dados ${ }^{7}$, sendo 0 ano referencial para esse estudo. O que se passou a observar é que os jovens-doutores se tornaram um ponto importante para as políticas de educação superior no país, justificadas por dois pontos chaves:

1) Pela necessidade de aumento qualificado de professores doutores universitários, especialmente, para atender às metas de expansão da Educação Superior, atingindo, assim, os objetivos do PNE e Reuni, objetivo também

\footnotetext{
7 A coleta de dados serve, principalmente, para avaliação dos programas de pós-graduação e, ainda, para formar a um acervo de informações, chamado de "memória da pós-graduação", referente a todo Sistema Nacional de Pós-Graduação - SNPG. Em março de 2014, a CAPES implementou um sistema integrado de coleta online. (CAPES, 2014).
} 


\section{Trabalhonecessário}

Issn: 1808 - 799X

ano 14, número $23-2016$

ressaltado no IV Plano Nacional de Pós-Graduação (PNPG), de 2005 a 2010, como primeiro PNPG a tratar do tema "expansão", de forma mais ampla, o qual apresenta dentre seus objetivos fundamentais:

uma expansão do sistema de pós-graduação que leve a expressivo aumento do número de pós-graduandos requeridos para a qualificação do sistema de ensino superior do país, do sistema de ciência e tecnologia e do setor empresarial. (MEC; CAPES, 2004, p. 9).

Prova disso é que, embora se constate uma contínua expansão da pósgraduação na década de 1990, o aumento significativo se dá a partir de 2008 e, apesar de o número de professores ter aumentado 108\% (1998-2012, ver tabela 1) em pouco mais de uma década, o de professores que se vincularam a Programas de Pós-Graduação evoluiu mais de $400 \%$ no mesmo período.

Este fato nos leva a inferir que a inserção de docentes na pós-graduação foi intensa, especialmente pelos 'novos' docentes contratados, pois temos como exemplo os jovens-doutores desta pesquisa, dentre os quais, $85 \%$ entraram na pós-graduação no primeiro ano de concursado. Os demais, que não se vincularam a nenhum Programa de pós-graduação no mesmo ano do concurso, citaram um entre três motivos: a) não se encontravam em departamento com Programa de pós-graduação em sua área; b) tiveram que elaborar e organizar um Programa de pós-graduação na área ou departamento; e, c) entraram num departamento bastante concorrido com Programa de Nota 6 ou 7 e precisaram esperar e trabalhar muito para ter currículo condizente com os critérios estabelecidos (dados compilados das entrevistas e do currículo lattes).

Se tais motivos se reproduziram nas demais universidades do Brasil, justificariam o aumento no número de docentes na pós-graduação e a criação, 


\section{Trabalhonecessário}

Issn: 1808 - 799X

ano 14, número $23-2016$

entre 2000 e 2012, de 925 cursos de doutorado e 1.662, de mestrado. (GEOCAPES, 2000; 2012)

2) Os professores jovens-doutores são foco de políticas de pesquisa, geralmente relacionadas a bolsas e 'Programas de Recém-Doutores', concursados em Universidades Federais e com menos de 5 anos de formação doutoral. Tem-se, como exemplo, o 'Programa Recém-Doutor' na UFSCar, iniciado em 2004, sob responsabilidade da Pró-Reitoria de Pós-Graduação e Pesquisa ${ }^{8}$, com o objetivo de "[...] apoiar o recém-doutor visando o auxílio ao desenvolvimento da pesquisa emergente na Universidade." (UFSCAR, 2004, p. 1)

Tem-se, ainda, o Programa Nacional de Pós-Doutorado (PNPD), criado pela Portaria Interministerial n. 20, de 27 de abril de 2007, em ação conjunta com a Coordenação de Aperfeiçoamento de Pessoal de Nível Superior do Ministério da Educação (CAPES/MEC), o Conselho Nacional de Desenvolvimento Científico e Tecnológico (CNPq) e a Financiadora de Estudos e Projetos (FINEP), órgãos do Ministério da Ciência e Tecnologia, com intuito de apoiar recém-doutores, ainda não concursados, e financiá-los em áreas estratégicas de pesquisa relacionadas à política industrial, tecnológica e de comércio:

\footnotetext{
Art. 50 - Para a execução do PNPD, as agências federais mencionadas convocarão, por edital conjunto, instituições de ensino superior, centros de pesquisa, programas de pósgraduação e empresas da área tecnológica para apresentar projetos de pesquisa, visando à concessão de bolsas de pósdoutorado a candidatos titulados nos últimos cinco anos e que estejam vinculados ou aceitem se vincular aos projetos apresentados ao edital, tendo prioridade os projetos que envolvam a interação universidade/centro de pesquisa-empresa e/ou de formação de pós-graduandos, prevendo-se também a concessão de recursos de custeio aos mesmos. (MEC; MCT, 2007, p. 1, grifo nosso).
}

\footnotetext{
${ }^{8}$ Cf.: <www.propg.ufscar.br>.
} 


\section{Trabalhonecessário}

Issn: 1808 - 799X

ano 14, número $23-2016$

Os dois pontos citados demonstram que a Universidade e as agências de fomento à pesquisa, como CAPES, CNPq e FINEP, não só consideram os jovens doutores como potência no âmbito da pesquisa como também apregoam que devem ser absorvidos, concursados ou não, com carga horária integral por universidades (e, consequentemente, por grupos de pesquisa), centros/institutos de pesquisas e empresas, especialmente nas áreas tecnológicas (MEC; MCT, 2007) e, além disso, incentivados à alta produção, com bolsas em pesquisa.

Um exemplo de bolsa relacionada à produção científica é a chamada Bolsa Produtividade em Pesquisa (Bolsa PQ), que é "destinada aos pesquisadores que se destaquem entre seus pares, valorizando sua produção científica segundo critérios normativos, estabelecidos pelo CNPq, e específicos, pelos Comitês de Assessoramento (CA)" (CNPQ, 2014, p. 1).

Em nossa pesquisa, a Universidade Federal de São Carlos (UFSCar) foi escolhida como lócus da investigação. Para isso, foram considerados os professores que se enquadram na denominação de "jovem-doutor" na UFSCar, com vínculos em Programa de Pós-Graduação e com bolsa $P Q^{9}$, resultando no total de 27 professores jovens-doutores, vinculados a 14 Programas de PósGraduação da UFSCar, representando 30\% (14 do total de 47) dos Programas da instituição.

Informações sobre a produção acadêmico-científica desses jovens doutores, a entrevista, com perguntas elaboradas a partir das temáticas acerca da vida pessoal e da formação acadêmica; o trabalho na UFSCar (concurso e processo de expansão); a pesquisa e a pós-graduação; e o cotidiano de trabalho possibilitaram a organização de um banco de dados e suscitaram reflexão sobre o

\footnotetext{
${ }^{9}$ Resultado identificado a partir dos contemplados nos editais de 'Bolsa PQ' nos anos de 2009 a 2012, considerando o tempo máximo de validação da bolsa (4 anos).
} 


\section{Trabalhonecessário}

Issn: 1808 - 799X

ano 14, número $23-2016$

trabalho como tema definidor do próprio ser do homem, em uma dimensão ontológica, e contraditória, exposta, neste artigo, em dois itens que tratam não só da produção desses jovens doutores como também de seu cotidiano na atual conjuntura político-econômica da Universidade.

\section{O Jovem-Doutor e a produção científica: o exemplo da UFSCar}

Os jovens-doutores selecionados para esta pesquisa, além de formados a partir de 2004 e estarem com até 10 anos de carreira docente na UFSCar, atuam na pós-graduação e já gozam do status de pesquisadores reconhecidos com bolsa Produtividade em Pesquisa (PQ/CNPq), também chamada de 'Bolsa PQ'.

Apresenta-se, a seguir, a Tabela 1, com identificação dos sujeitos da pesquisa, por área, ano de doutoramento, quantidade de pós-doutorado concluído, bem como o ano de ingresso como professor universitário na UFSCar e suas respectivas categorias/nível de bolsa PQ.

Tabela 1 - UFSCar - Identificação dos Jovens-Doutores com bolsa Produtividade em

Pesquisa, por códigos de identificação, ano de doutorado, quantidade de pósdoutoramento e ingresso na UFSCar. Jan. 2014

\begin{tabular}{|c|c|c|c|c|c|c|c|}
\hline $\begin{array}{l}\text { Cód. Sujeitos } \\
\text { da Pesquisa }\end{array}$ & Grande Área & $\begin{array}{c}\text { Ano } \\
\text { Doutorad } \\
0\end{array}$ & $\begin{array}{c}\mathrm{Nu} \\
\mathrm{m} \\
\text { Pós } \\
- \\
\text { Doc }\end{array}$ & $\begin{array}{c}\text { Pós- } \\
\text { Doc } \\
1\end{array}$ & Pós-Doc2 & $\begin{array}{c}\text { Concurs } \\
0 \\
\text { UFSCar }\end{array}$ & $\begin{array}{l}\text { Bolsa PQ } \\
\text { (LATTES) }\end{array}$ \\
\hline CE1.0509 & \multirow{8}{*}{$\begin{array}{c}\text { Ciências } \\
\text { Exatas e da } \\
\text { Terra }\end{array}$} & 2005 & 1 & 2006 & & 2009 & PQ2 \\
\hline CE2.0508 & & 2005 & 4 & 2007 & 2008 & 2008 & PQ2 \\
\hline CE3.0404 & & 2004 & 2 & 2004 & 2010 & 2004 & PQ2 \\
\hline CE4.0709 & & 2007 & 1 & 2009 & & 2009 & PQ2 \\
\hline CE5.0406 & & 2004 & 2 & 2004 & 2006 & 2006 & PQ2 \\
\hline CE6.0408 & & 2004 & 2 & 2006 & 2008 & 2008 & PQ2 \\
\hline CE7.0409 & & 2004 & 4 & 2005 & $2006 ; 2008$ & 2009 & PQ2 \\
\hline CE8.0409 & & 2006 & 2 & 2008 & 2009 & 2009 & PQ2 \\
\hline CE9.0609 & & 2006 & 2 & 2006 & 2009 & 2009 & PQ2 \\
\hline CE10.0509 & & 2005 & 3 & 2005 & 2007 & 2009 & PQ2 \\
\hline
\end{tabular}




\section{Trabalhonecessário}

Issn: 1808 - 799X

ano 14, número $23-2016$

\begin{tabular}{|c|c|c|c|c|c|c|c|}
\hline CE11.0610 & & 2006 & 2 & 2007 & 2008 & 2010 & PQ2 \\
\hline CE12.0406 & & 2004 & 2 & 2006 & 2013 & 2006 & PQ2 \\
\hline CE13.0710 & & 2007 & 2 & 2008 & 2009 & 2010 & PQ1D \\
\hline $\begin{array}{l}\text { Cód. Sujeitos } \\
\text { da Pesquisa }\end{array}$ & Grande Área & $\begin{array}{c}\text { Ano } \\
\text { Doutorad } \\
0\end{array}$ & $\begin{array}{c}\text { Nu } \\
\text { m } \\
\text { Pós } \\
- \\
\text { Doc }\end{array}$ & $\begin{array}{l}\text { Pós- } \\
\text { Doc } \\
1\end{array}$ & Pós-Doc2 & $\begin{array}{c}\text { Concurs } \\
\text { o } \\
\text { UFSCar }\end{array}$ & $\begin{array}{l}\text { Bolsa PQ } \\
\text { (LATTES) }\end{array}$ \\
\hline CB14.0809 & Ciências & 2008 & 1 & 2009 & 2009 & 2009 & PQ2 \\
\hline CB15.0608 & Biológicas & 2006 & 1 & 2008 & & 2008 & PQ2 \\
\hline ENG16.0410 & & 2004 & 1 & 2006 & & 2010 & PQ2 \\
\hline ENG17.0609 & & 2006 & 0 & & & 2009 & PQ2 \\
\hline ENG18.0609 & Engenharias & 2006 & 1 & 2009 & & 2009 & PQ2 \\
\hline ENG19.0404 & & 2004 & 2 & 2007 & 2008 & 2004 & PQ1D \\
\hline ENG20.0806 & & 2008 & 0 & & & 2006 & PQ2 \\
\hline CS21.0404 & Ciências da & 2004 & 1 & 2008 & & 2004 & PQ1C \\
\hline CS22.0604 & Saúde & 2006 & 1 & 2014 & & 2004 & PQ2 \\
\hline CSA23.0402 & $\begin{array}{c}\text { Ciências } \\
\text { Sociais } \\
\text { Aplicadas }\end{array}$ & 2004 & 0 & & & 2002 & PQ2 \\
\hline $\mathrm{CH} 24.0405$ & \multirow{4}{*}{$\begin{array}{l}\text { Ciências } \\
\text { Humanas }\end{array}$} & 2004 & 0 & & & 2005 & PQ2 \\
\hline $\mathrm{CH} 25.0809$ & & 2008 & 1 & 2009 & & 2009 & PQ2 \\
\hline $\mathrm{CH} 26.0410$ & & 2004 & 0 & & & 2010 & PQ2 \\
\hline $\mathrm{CH} 27.0606$ & & 2006 & 1 & 2011 & & 2006 & PQ2 \\
\hline
\end{tabular}

Fonte: CNPq, Plataforma Lattes: Currículo Lattes (consultas e atualizações de dados em mar. 2013 e fev. 2014). Elaboração Própria.

No momento que se organizavam os dados dos docentes, instituiu-se um código, demonstrado na primeira coluna da Tabela 1, justamente para tornar representativo o discurso do professor e contribuir como elemento de análise durante o estudo. $O$ código se organiza da seguinte forma: as letras iniciais se referem à grande área a que o professor pertence, seguida da ordem numérica de organização e, após o ponto, os dígitos identificam o ano em que o professor se doutorou e o ano em que ingressou na UFSCar, por exemplo, o professor $\mathrm{CH} 25.0809$ pertence à área de Ciências Humanas, estava na ordem 25, doutorou-se em 2008 e entrou na UFSCar em 2009.

Em relação às grandes áreas de conhecimento, observa-se que, no universo de professores jovens-doutores, cerca de 50\% são das áreas de 


\section{Trabalhonecessário}

Issn: 1808 - 799X

ano 14, número $23-2016$

Ciências Exatas, que contemplam professores que se graduaram nas seguintes subáreas: física, matemática, química e ciência da computação; depois, têm-se as áreas das Engenharias, com 18,5\%, e subáreas de engenharia de materiais, engenharia elétrica, engenharia de produção e engenharia química; as de Ciências Humanas com 14\%, e subáreas sociologia, filosofia, antropologia e psicologia, nas quais não se identificou nenhum professor da área de Educação. As demais, ciências biológicas, sociais aplicadas e da saúde, somam 18,5\%, relações percentuais que representam também a prioridade em áreas das chamadas ciências duras e de inovação.

A partir dos dados e das falas, foi possível remeter-se às questões iniciais da investigação e chegar-se, primeiramente, às considerações relativas à segunda questão, na qual se indaga sobre a possibilidade de se elaborar um perfil dos jovens-doutores com bolsa produtividade, em relação ao contexto que vivenciam na profissão docente, especialmente na pós-graduação. Entende-se que o 'perfil' que se traçou não é totalmente rígido ou determinado, mas algo que se apresenta como o esforço didático de organizar um conjunto de identificações que relacionaram os professores jovens-doutores no decorrer da pesquisa, como pontos de intercessão entre os mesmos, os quais se apresentam em seis pontos interligados:

1) Os jovens-doutores, a exemplo do que se delineou sobre a formação dos professores da UFSCar, formaram-se em instituições de alto valor acadêmico, públicas, e em grupos de pesquisa. Observou-se que $100 \%$ dos professores estudaram em reconhecidas universidades públicas, estaduais e federais. Destes, $81 \%$ cursaram a qualificação de pós-doutoramento, e cerca de $45 \%$ deles o fizeram duas vezes ou mais, com representação para as instituições estrangeiras (64\%). Os cursos de pós-doutorado foram 100\% financiados com bolsas de pesquisa de agências públicas. A única instituição privada que se fez 


\section{Trabalhonecessário}

Issn: 1808 - 799X

ano 14, número $23-2016$

presente na formação dos jovens doutores foi a Pontifícia Universidade Católica de Campinas (PUCCAMP), no período de graduação. Nos demais graus, mestrado e doutorado, todas as instituições foram públicas.

2) Apresentam, no histórico, contínuo de financiamento no decorrer de sua jovem carreira, com bolsas de estudo no período de formação: "na graduação, 63\% (com bolsa de Iniciação Científica - IC); no mestrado, 85\%; e, no doutorado, 92,5\%, com exceção de dois: um da área da Engenharia (ENG.17.0609), que trabalhava na época do doutorado, e foi, por isso, impedido de receber bolsa, e o outro, na área de humanas (CH24.0405)" (Cf. p.133). Além disso, todos receberam bolsas de pós-doutorado, bolsa produtividade e financiamentos de pesquisas.

3) Revelam constante preocupação com o currículo, que reverbera na quantidade da produção científica, no número de citações, em índices de impacto e na internacionalização da produção científica, quando $85 \%$ dos professores jovens-doutores "assumiram que a preocupação atual está em escrever para revistas de maior impacto". Notou-se, também, que os $15 \%$, correspondentes a quatro professores que não citaram o impacto das revistas são "professores com menor ou nenhuma citação indexada, e maior produção em livros, capítulos e eventos, que se concentram nas áreas das humanidades" (Cf. FERREIRA, 2015, p.138). Todos os professores atuavam em, ao menos, um projeto de pesquisa em andamento, e entre os 107 projetos ativos, 51\% são coordenados por apenas seis jovens-doutores (CE8.0409; ENG16.0410; ENG19.0404; CS21.0404; CS22.0604; $\mathrm{CH} 27.0606)$, "os quais são envolvidos em sete ou mais projetos cada um".

Todos são revisores de pelo menos uma/um revista/periódico, sendo que $85 \%$ atuam em três ou mais revistas. Fazem consultoria ad hoc para revistas e agências de fomento e mantêm parcerias com instituições estrangeiras, especialmente em pesquisas e publicações. 


\section{Trabalhonecessário}

Issn: 1808 - 799X

ano 14, número $23-2016$

4) Adotam a pesquisa e a internacionalização como pólo central do trabalho docente, com cerca de $80 \%$ do professores ratificando a centralidade da pesquisa em seu trabalho (Cf. p. 146-148), que se justifica pelo fato de a carreira de pesquisador estar atrelada à de professor nas universidades do Brasil. Por isso, embora a maioria declare o 'gosto de ensinar na graduação', a paixão e o prazer na carreira estão na pesquisa, não no ensino. Desse modo, pode-se entender porque a pós-graduação tomou um lugar importante no trabalho na universidade, consolidando-se como lócus de pesquisa, seja pelo que ela proporciona em relação a recursos humanos, com alunos de mestrado, doutorado e pós-doutorado, engajados em pesquisa, ou mesmo, pelas influências que o vínculo a um programa de pós-graduação confere ao pesquisador, em relação aos critérios de financiamento pelas agências de fomento, CAPES, CNPq e fundações estaduais, como a FAPESP.

Dos professores entrevistados, $81 \%$ relataram que mantêm algum tipo de parceria com instituições estrangeiras, especialmente em pesquisas e publicações. Isso pode ser constatado, ao se verificar, por exemplo, as publicações de artigos em periódicos indexados (Cadastro no Webof Science), com produções em inglês, apresentadas na Tabela 2:

Tabela 2 - UFSCar - Total de artigos em inglês publicados em periódicos indexados, por 'grande área do conhecimento', 2000 a 2013

\begin{tabular}{l|c|c|c|c|c|c}
\hline \multicolumn{1}{c|}{ Grandes Áreas } & $\begin{array}{c}\text { Ciências } \\
\text { Exatas e } \\
\text { Terra }\end{array}$ & $\begin{array}{c}\text { Ciências } \\
\text { Biológicas }\end{array}$ & Engenharias & $\begin{array}{c}\text { Ciências } \\
\text { Saúde }\end{array}$ & $\begin{array}{c}\text { Ciências } \\
\text { Sociais } \\
\text { Aplicadas }\end{array}$ & $\begin{array}{c}\text { Ciências } \\
\text { Humanas }\end{array}$ \\
\hline $\begin{array}{l}\text { Total de publicação } \\
\text { de artigos em } \\
\text { Periódicos }\end{array}$ & 474 & 19 & 153 & 150 & 35 & 71 \\
\hline $\begin{array}{l}\text { Qtd do total de } \\
\text { artigos publicados } \\
\text { em inglês }\end{array}$ & 451 & 19 & 120 & 116 & 0 & 3 \\
\hline $\begin{array}{l}\% \text { correspondente } \\
\text { ao Total }\end{array}$ & $\mathbf{9 5 , 1}$ & $\mathbf{1 0 0}$ & $\mathbf{7 8 , 4}$ & $\mathbf{7 7 , 3}$ & $\mathbf{0}$ & $\mathbf{4 , 2}$ \\
\hline
\end{tabular}

Fonte: CNPq, Plataforma Lattes/Currículo, consultas em mar. 2013 e jan. 2014. Elaboração Própria. 


\section{Trabalhonecessário}

Issn: 1808 - 799X

ano 14, número $23-2016$

Para compor a Tabela 2, foi necessário verificar, em cada currículo, o tema da publicação e os periódicos publicados. É interessante observar que foram encontrados periódicos brasileiros com todos artigos publicados em inglês, chegando-se à obviedade que, em determinadas ciências (exatas, biológicas, engenharias e saúde), a publicação em inglês parece uma regra, podendo-se, inclusive, demarcar nestas áreas as poucas publicações em língua materna, especialmente entre os anos de 2000 a 2006, período em que a maioria ainda se encontrava na condição de alunos de pós-graduação.

Esclarece esta questão o coordenador do programa SciELO, Sr. Abel Packer, em entrevista para a FAPESP, o qual destacou a questão da internacionalização se naturalizando na produção científica do país como algo positivo:

"Está ocorrendo um fenômeno impressionante no Brasil: a publicação cada vez maior de artigos científicos em inglês nas revistas nacionais", disse Packer. "Nos últimos três anos, temos acompanhado um aumento e, em 2012, eles corresponderam a mais da metade dos artigos publicados." De acordo com dados do último relatório da Rede SciELO, o número de artigos científicos publicados em inglês em revistas brasileiras integrantes da SciELO Brasil saltou de 38\% em 2007 para 52\% em 2012. Além disso, também aumentou a publicação de artigos bilíngues (em português e inglês). (ALISSON, 2013, s/p).

E, embora as ciências humanas ainda estejam a lograr um caminho de parcerias e publicações em outros idiomas, que, na UFSCar, entre os jovensdoutores, não chegam a 5\%, Packer enfatiza que, seguida da área da saúde, que tem o maior número de publicações, a de Ciências Humanas foi a que mais adotou a estratégia de publicação bilíngue - português e inglês - em artigos de revistas brasileiras. (ALISSON, 2013). 


\section{Trabalhonecessário}

Issn: 1808 - 799X

ano 14, número $23-2016$

5) Reproduzem com seus alunos de pós-graduação a formação que obtiveram, constatando-se que a formação do professor-pesquisador, nos moldes do produtivismo acadêmico e financiamento de bolsas e projetos, foi confirmada em relação aos seus orientandos, por $84 \%$, que, além de trabalharem em modo de cooperação na produção científica, muitas vezes, se " $[\ldots]$ guiam pelos documentos internos da pós-graduação, como mecanismo institucional de indução, para exigir de seus alunos determinada produção" (FERREIRA, 2015, p. 154), neste caso, trabalhando em um processo autoritário de orientação, ditando regras e temas de pesquisa que acabam por induzir as pesquisas e projetos dos alunos. Nesse ponto, vale lembrar a contradição exposta na relação professoraluno, entre "o cuidado e a dinâmica na formação humana e as exigências institucionais da pós-graduação e estratégias para publicação", voltadas à formação de um 'currículo'.

6) Naturalizam uma prática acadêmica relacionada com o trabalho competitivo e empreendedor, na qual se expressa um "perfil de pesquisadores que parecem introduzir, em sua prática universitária, a competitividade e o empreendedorismo, tão almejados pelos documentos e planos nacionais de investimento em pesquisa, como o V PNPG (MEC; CAPES, 2010) e o ENCIT (BRASIL; MCTI, 2012)" (Cf. FERREIRA, 2015. p.133-134). Este ponto se liga diretamente com a utilização do conhecimento técnico-científico, em prol do desenvolvimento econômico empresarial, e com os financiamentos de projetos privados, que orientam o pesquisador em relação ao financiamento, à produção e aos grupos de pesquisa, criando capacidades e competências em áreas cada vez mais estratégicas.

Deste modo, considerando os dados apresentados, pode-se afirmar que os professores jovens-doutores estão entre os privilegiados professores com histórico de formação pública, altamente produtivos e que detêm reconhecido 


\section{Trabalhonecessário}

Issn: 1808 - 799X

ano 14, número $23-2016$

desempenho científico, considerando-se o número de projetos de pesquisa em andamento, os financiamentos aprovados, as publicações e os investimentos em Bolsa Produtividade pelo CNPq, e os respectivos índices de impacto (Web of Science; o Fator H, e outros). Ademais, observados nos Cadernos de Indicadores, avaliados pela CAPES, alcançam mais que a média nos critérios gerais de produção bibliográfica, técnica e de desempenho docente em sua área de atuação específica.

Evidentemente que todo este desempenho, quantitativamente considerável e qualitativamente diferenciado, pressupõe um esforço de trabalho contínuo, que difere, ou não, de seus pares na universidade. Mas o que dizem os professores jovens-doutores sobre seu trabalho e sobre seu cotidiano? Por isso, para além dos dados expostos, tem-se a necessidade de saber o que estes professores têm a dizer, constituindo, assim, as reflexões sobre o cotidiano e o trabalho, expostas no item a seguir.

\section{A racionalidade do discurso sobre o Trabalho}

Não, não tive filhos. Eu tenho vontade, mas me falta tempo, meu marido acho que não está querendo muito, e eu fico pensando nessa vida, né? Ele também. Não é docente, mas faz doutorado. [...]. Estamos naquela fase de ficar trabalhando vinte e quatro horas. [...]. Na verdade, nossa vida social está muito a desejar! Para o futuro? Bom, eu quero continuar com a bolsa produtividade, então eu vou mandar de novo quando fizerem os três anos. Assim eu quero chegar ao ápice da profissão e publicar muito. [...]. Eu quero conseguir também um auxilio da FAPESP, quero que saia logo esse projeto da Petrobras pra começar a mexer com laboratório, e até acho que não tenho vontade de ir para outro programa de Pós. Penso que vou ficar nesse mesmo, acho que minhas pretensões para o futuro são publicar mais $e$ conseguir mais financiamento, ter doutorandos e um aluno de pósdoutorado. É isso. (CB15.0608, p. 10-12, 2012, grifo nosso). 


\section{Trabalhonecessário}

Issn: 1808 - 799X

ano 14, número $23-2016$

O discurso desta professora demonstra, dentre tantos outros, a contradição vivenciada, de modo geral, entre os jovens-doutores pesquisadores, orientador e professor de pós-graduação, que se dividem entre os sentimentos de amor pelo trabalho e pela produção e comprometimento com as duas atividades e uma vida cotidiana composta de prazos, projetos, financiamento e relações pessoais comprometidas. Isso se dá a tal ponto que o ser social, em sua prática cotidiana se vê sempre diante de demandas da objetividade social e a elas responde de diversas maneiras em movimento histórico e contraditório. Por isso, grande parte dos depoimentos dos professores jovens-doutores aponta para esta cisão, referente ao aspecto contraditório no qual se encontram.

Silva Júnior et. al. (2014) afirmam que emerge deste movimento a "tensão entre indivíduo e totalidade: o novo ser social professor" e acrescentam, que

não há como continuar produzindo pesquisas de grande quilate sem se submeter aos critérios de avaliação, financiamento e a todo o desenrolar deste processo, mas também não há como deixar de fazê-lo, sob pena de ter estanque seu próprio trabalho. No entanto, aceitando as condições impostas em favor da execução de seu trabalho, este trabalho não mais lhe pertence, na medida em que a primeira aceitação implica também na assimilação das diretivas impostas por este sistema. (SILVA JÚNIOR et al., 2014, p. 196-197).

Isso não significa que o professor que 'aceita' e 'naturaliza' este modo de produção do conhecimento e de vida consente com as determinações possíveis deste processo no cotidiano, no qual uma cultura de trabalho the é imposta. Exemplo disso é o que vive a professora CE15.0608, que se doutorou em 2005, ingressou como docente em 2008, e, antes dos cinco anos na universidade (em 2012), abraça, como perspectiva de futuro, prioritariamente, as realizações profissionais relacionadas à pesquisa, à produção, às agências e empresas de 


\section{Trabalhonecessário}

Issn: 1808 - 799X

ano 14, número $23-2016$

financiamento, e à quantidade de alunos de pós-graduação e pós-doutorado, e que, assim como outros professores, quer galgar o "ápice da profissão".

Ao compreender que os pontos mencionados se relacionam entre si na vida cotidiana dos professores, tem-se condição de refletir a respeito dos depoimentos dos professores sobre seu trabalho. Nesse sentido, é possível inferir que o perfil dos professores jovens-doutores caracteriza sua postura na universidade, na qual o discurso se concentrou entre duas dimensões contraditórias: a paixão pelo trabalho docente e a pressão e estranhamento causados pelo mesmo.

O primeiro se apresenta desde o momento de escolha da área de formação, da carreira docente, à aprovação num concurso, e às pesquisas realizadas, conforme alguns relatos: "difícil alguém pensar o contrário, você sonha em ser docente, [...], então você passa algum dia num concurso, e tudo começa a fazer mais sentido, [...], todos os conceitos vão mudar, mas a paixão pela profissão e o prazer em fazer pesquisa, sempre permanecem." (CE8.0409, 2012, p. 11)

Os autores Sguissardi e Silva Júnior (2009) também se depararam com diversos depoimentos relacionados à paixão e ao prazer da carreira, e, após os relatos de professores sobre o assunto, apontaram:

Pode-se dizer que este prazer não é real? Evidentemente, não. Mas ele adquire sentido no contexto da cultura, que se tornou dominante, que valoriza o produtivismo acadêmico, a sociabilidade produtiva ou, por exemplo, a "produção" que, para ser mais valorizada, precisa ser publicada no exterior, nos veículos de divulgação científica dos países centrais e sob a chancela de suas instituições de pesquisa, além de em sua língua, o inglês, latim moderno, símbolo da dominação na atual fase do capital mundializado. (SGUISSARDI; SILVA JÚNIOR, 2009, p. 141-142). 


\section{Trabalhonecessário}

Issn: 1808 - 799X

ano 14, número $23-2016$

O vigor ressaltado nas entrevistas, para além do discurso, demonstra os sentidos expostos nas expressões faciais, na entonação da voz, na alegria de expressar sua história de vida, de falar a respeito das pesquisas que desenvolvem, ou mesmo, do quanto produzem, do número importante de seu índice $\mathrm{H}$, ou sobre as revistas de impacto em que publicam. $\mathrm{O}$ prazer e paixão pelo trabalho científico-acadêmico externaram-se em diversos momentos, e à luz da resposta dos autores citados, pôde -se refletir sobre os critérios estabelecidos como parâmetros desse sentimento. Observa-se, na perspectiva teórica deste estudo, que o discurso sobre a paixão está tomado por questões que envolvem processos de conformismo e naturalização das condições postas para o trabalho e para a pesquisa, e que se revelam em estranhamento no próprio decorrer do discurso, quando um professor percebe, por exemplo, que nunca parou para pensar na quantidade de tempo que dispende para desempenhar o trabalho, ou que não percebeu que trabalha de domingo a domingo. Isso é reforçado, ainda, em relatos de casamentos desfeitos, problemas de saúde e jovens com menos de 35 anos sem perspectivas de terem filhos ou família, constatando que passaram, entre seus 20 e 30 anos, engajados na formação de um currículo amarrado ao financiamento de suas pesquisas, não em lutas por salário, por exemplo.

Nesse sentido, emerge a segunda dimensão: a pressão que dizem sentir $89 \%$ dos entrevistados, caracterizada pelas circunstâncias de critérios e metas que os impulsionam "de todos os lados" (FERREIRA, 2015, p. 158), sobre as quais se estabelecem relações no trabalho, especialmente no âmbito da pósgraduação e das pesquisas que necessitam de financiamento para se efetivarem e as quais se colocam na universidade não pela via institucional, mas pelo 'mérito', em processos de seleção de agências de fomento.

Tal contexto propicia a intensificação do trabalho, a dinâmica em multitarefas, que, por vezes, resulta em processos sofridos de produção. Os 


\section{Trabalhonecessário}

Issn: 1808 - 799X

ano 14, número $23-2016$

depoimentos expostos neste estudo mencionam, ainda, condições objetivas dos programas de pós-graduação e precária infraestrutura por parte da universidade, o que, de modo geral, potencializa o stress e o sofrimento em relação ao trabalho. Da falta de apoio técnico, de estruturas de laboratórios e de salas de pesquisas, até a cobrança de produtividade, tudo se engendra numa espécie de mecanismo de indução a pesquisas, à busca por financiamentos e a um novo modelo de produção de conhecimento.

$\mathrm{Na}$ reflexão sobre todo este processo, que continua em movimento, podese compreender que o trabalho intelectual do professor jovem-doutor está na estrutura que o Estado oferece para a produção de conhecimento e pósgraduação, cada vez mais ligados ao que Marx escreveu no 'Grundrisse', no âmbito do que denominou de general intellect (MARX, 2011) ${ }^{10}$, segundo o qual, o trabalho intelectual passa a contar no avanço do processo produtivo e se funde na produção material diante da lógica das relações de produção:

o desenvolvimento do capital fixo indica até que ponto o saber social geral, conhecimento, deveio força produtiva imediata e, em consequência, até que ponto as próprias condições do processo vital da sociedade ficaram sob o controle do intelecto geral e foram reorganizados em conformidade com ele. Até que ponto as forças produtivas da sociedade são produzidas, não só na forma do saber, mas como órgãos imediatos da práxis social; do processo real da vida. (MARX, 2011, p. 589).

O conhecimento começa a obter, nos âmbitos institucional, nacional e internacional, um papel crucial no desenvolvimento da sociedade capitalista,

\footnotetext{
${ }^{10}$ Marx (2011, p. 589, grifos nossos) quando trata do 'general intellect' ou 'intelecto geral', ressalta a função do homem ao modificar a natureza, pois "a natureza não constrói máquinas, nem locomotivas, ferrovias, telégrafos elétricos, máquinas de fiar automáticas etc. Elas são produtos da indústria humana; material natural transformado em órgãos da vontade humana sobre a natureza ou de sua atividade na natureza". Destacando-se como "órgãos do cérebro humano criados pela mão humana; força do saber objetivado".
} 


\section{Trabalhonecessário}

Issn: 1808 - 799X

ano 14, número $23-2016$

passando, assim, a desenvolver as forças produtivas e a mudar profundamente os meios de controle e regulação do país o que, ao mesmo tempo, provoca consequências negativas para a universidade, espaço primordial da formação humana e da produção intelectual.

Do ponto de vista da economia política, o trabalho do professor, aos moldes dos jovens-doutores, significa um processo que vai reposicionar a universidade pública a serviço da valorização do capital, como já anunciava Francisco de Oliveira (2009), sob um novo paradigma de produção de conhecimento, no qual, a centralidade do trabalho intelectual na universidade toma lugar especial no capitalismo contemporâneo.

\section{Considerações finais}

Importante frisar que em momento algum se analisaram dados, documentos e discursos à luz da 'improdutividade docente' ou em defesa de um professor sem financiamento. $O$ que se buscou foi apreender a realidade conferida pela atual conjuntura de trabalho e a maneira como os professores jovens-doutores declaram vivenciar tal processo, que poderia, sim, tomar novos rumos e atitudes de resistência à intensificação do trabalho e ao produtivismo que faz da produção salutar de conhecimento, um processo de quantificação da produção. Todavia, a resistência pode começar no individual, mas só tomará forma pelo coletivo, principalmente sindical. 


\section{Trabalhonecessário}

Issn: 1808 - 799X

ano 14, número $23-2016$

Faz-se, neste momento, menção ao que o Sindicato Nacional dos Docentes das Instituições de Ensino Superior (ANDES-SN) ${ }^{11}$ sugere para a universidade brasileira, na "Proposta do Andes-SN para a Universidade Brasileira", elaborada a partir de discussões, em 1981, com sua primeira versão, em junho de 1982, após o V Conselho Nacional de Associações Docentes (V CONAD), realizado em Belo Horizonte/MG, e apresentada ao Ministério da Educação e Cultura no mesmo ano, encontrando-se na $4^{\text {a }}$ versão revisada, em 2013. (ANDES-SN, 2013, p. 11)

Para desenvolver este modelo de Universidade, ter-se-ia a necessidade de sua "manutenção e ampliação" sob responsabilidade do Estado, com a organização e o funcionamento, garantindo, entre outros fatores, que "[...] seja mantido um sistema de avaliação institucional do tripé ensino, pesquisa e extensão, entendido como retrospectiva crítica, contextualizado nas demandas sociais e nas condições reais em que se dá o trabalho acadêmico.", tendo-se como objetivo a melhora da qualidade, "[...] referenciada em processos e não apenas em produtos." (ANDES-SN, 2013, p. 18)

Compreender, portanto, a complexidade histórica das transformações político-econômicas do Brasil e suas relações com a internacionalização da produção e com o trabalho, especialmente o trabalho intelectual, agora mais orientado pelas relações econômicas, foi fundamental para entender a influência do capital nas relações humanas, especialmente naquelas mais observadas a partir das falas sobre o cotidiano e as relações de trabalho.

Esta pesquisa propiciou ao pesquisador a proximidade com a realidade do docente, no campo da especificidade do trabalho de professores jovens-

\footnotetext{
${ }^{11}$ A Associação Nacional dos Docentes de Ensino Superior (ANDES), fundada em 1981, "após a promulgação da Constituição de 1988. Os docentes, reunidos no II Congresso Extraordinário (Rio de Janeiro/RJ, novembro de 1988), aprovaram a transformação da ANDES em Sindicato Nacional dos Docentes das Instituições de Ensino Superior, o ANDES-SN. (ANDES-SN, 2013, p. 12-13).
} 


\section{Trabalhonecessário}

Issn: 1808 - 799X

ano 14, número $23-2016$

doutores, com menos de uma década na carreira, e se propôs a demonstrar o exercício de compreensão da realidade o que, por sua vez, possibilitou uma reflexão sobre seu próprio futuro, entre os professores e seus pares, por meio do discurso sobre si mesmos.

\section{Referências}

ALISSON, Elton. Número de artigos em inglês supera os publicados em português na SciELO Brasil.[online]. São Paulo: Notícias FAPESP. 25 de outubro de 2013. Disponível em: http://agencia.fapesp.br/numero_de_artigos_em_ingles_supera_os_publicados_e m_portugues_na_scielo_brasil/18109/

ANDES-SN. SINDICATO NACIONAL DOS DOCENTES DAS INSTITUIÇÕES DE ENSINO SUPERIOR. Proposta do Andes-SN para a Universidade Brasileira. $4^{\circ}$ versão revisada, Brasília: ANDES-SN, 2013.

BRASIL, Ministério da Ciência, Tecnologia e Inovação. Estratégia Nacional de Ciência, Tecnologia e Inovação 2012 - 2015. Brasília: MCTI, 2012. Disponível em: < http://www.mct.gov.br/upd_blob/0218/218981.pdf>. Acesso em: 20 mai, 2014.

COORDENAÇÃO DE APERFEIÇOAMENTO DE PESSOAL DE NÍVEL SUPERIOR. Coleta de Dados: conceitos e orientações. Manual de preenchimento da Plataforma Sucupira. Versão 7.1. Brasília: CAPES. 16 set, 2014. Disponível em: < file:///C:/Users/Luciana/Downloads/Coleta\%20de\%20Dados\%20\%20Conceitua\%C3\%A7\%C3\%A30\%20+\%20tecnico\%20v\%201.7.pdf>. Acesso: 29 ago, 2014.

DANTAS, Elza Ezilda Valente. O trabalho docente nas veredas históricas da Educação Brasileira. 180 f. Dissertação (Mestrado em Educação). Centro de Educação. Universidade Federal do Pará. Belém, PA. 2006.

FERREIRA, Luciana Rodrigues. O trabalho do Professor jovem-doutor na pósgraduação: produção de conhecimento e discurso do professor. 2015. 204 f. Tese (Doutorado em Educação). Universidade Federal de São Carlos, SP, 2015. 


\section{Trabalhonecessário}

Issn: 1808 - 799X

ano 14, número $23-2016$

FUNDAÇÃO DE AMPARO À PESQUISA DO ESTADO DE SÃO PAULO. Criação e Estruturação da FAPESP. [online]. São Paulo: FAPESP, 2014. Disponível em: http://www.fapesp.br/28. Acesso em: 02 dez, 2014.

GEOCAPES. Distribuição de Programas de Pós-Graduação 2004 a 2012. Visão Analítica. Região Sudeste. Planilha do Excel por Instituição, 2012. Disponível em: http://geocapes.capes.gov.br/geocapesds/\#. Acesso em: 27 jan, 2014.

GRUPO DE ECONOMIA POLÍTICA DA EDUCAÇÃO, ESTÉTICA E FORMAÇÃO HUMANA. Breve Histórico do Grupo de Pesquisas sobre Economia Política, Estética e Formação Humana - GEPEFH. [online]. São Carlos: GEPEFH/UFSCar, 2014.

GUIMARÃES, Rodrigues André. Trabalho Docente Universitário: participação dos professores na materialização da contrarreforma da educação superior na UFPA. 2014. 284f. Tese. (Doutorado). Universidade Federal do Pará, Instituto de Ciências da Educação. Belém, 2014.

INSTITUTO NACIONAL DE ESTUDOS E PESQUISAS EDUCACIONAIS. Censo da educação superior: sinopse estatística - 2000 a 2013. Brasília: INEP, 2014. Disponível em: http://download.inep.gov.br/informacoes_estatisticas/sinopses_estatisticas/sinops es_educacao_superior/sinopse_educacáo_superior_2013.zip. Acesso em: 12 nov, 2014.

LANCILLOTTI, Samira Saad Pulchério. A constituição histórica do processo de trabalho docente. 2008. 226f. Tese. (Doutorado). Universidade Estadual de Campinas, Faculdade de Educação. Campinas, 2008.

LEMOS, Jadis Camargo. Cargas psíquicas no trabalho e processos de saúde em professors universitários. $147 \mathrm{f}$. Tese (Doutorado). Centro Tecnológico. Universidade Federal de Santa Catarina. Florianópolis, 2005.

LIMA, Kátia. Precarização e intensificação: as novas faces do trabalho docente. Revista Universidade \& Sociedade. Brasília,v. 47, p. 149-159, 2011.

LUKÁCS, György. Para uma ontologia do ser social II. São Paulo: Boitempo, 2013.

MANCEBO, Deise. Trabalho docente e produção de conhecimento. Psicologia \& Sociedade (Online), v. 25, p. 519-526, 2013. Disponível em: http://www.scielo.br/pdf/psoc/v25n3/06.pdf, Acesso em: 20 jul, 2014. 


\section{Trabalhonecessário}

Issn: 1808 - 799X

ano 14, número $23-2016$

MANCEBO, Deise. Trabalho docente na educação superior: tensões e novos sentidos no Brasil. In: OLIVEIRA, Dalila; FELDFEBER, Myriam; MARTINEZ, Deolidia. (Org.). Nuevas regulaciones educativas en América Latina. Lima: Fondo Editorial, 2010, p. 287-310.

MANCEBO, Deise. Uma análise da produção escrita sobre o trabalho docente em tempos de globalização. In: Deise Mancebo; Maria de Lourdes de Albuquerque Fávero. (Org.). Universidade: políticas, avaliação e trabalho docente. 1ํe․ São Paulo: Cortez, 2004, p. 235-250.

MANCEBO, Deise; SILVA JÚNIOR, João dos Reis. Trabalho docente e expansão da educação superior brasileira. 1. ed. v. 1. 185p. Rio de Janeiro: EDUERJ, 2012.

MARX, Karl. Grundrisse: manuscritos econômicos de 1857-1858: esboços da crítica a economia política. São Paulo: Boitempo; Rio de Janeiro: Ed. UFRJ, 2011.

MAUÉS, Olgaíses Cabral. A reconfiguração do trabalho docente na educação superior. Educar em Revista. Dossiê: trabalho docente: condições, conjuntura e contexto. n. especial 1, Curitiba, PR: Editora UFPR, p. 141-160, 2010. Disponível em: $\quad$ http://www.scielo.br/scielo.php?script=sci_arttext\&pid=S010440602010000400007. Acesso em: 20 jul, 2014.

MINISTÉRIO DA EDUCAÇÃO. Coordenação de Aperfeiçoamento de Pessoal de Nível Superior. IV PNPG - Plano Nacional de pós-graduação (2005-2010). Brasília, DF: MEC/CAPES, dez. 2004.

OLIVEIRA, Francisco de. Prefácio - Recuperando a visão?. In: SGUISSARDI, Valdemar; SILVA JÚNIOR, João dos Reis. Trabalho intensificado nas federais: pós-graduação e produtivismo acadêmico. São Paulo: Xamã, 2009

SAGRILLO, Daniele Rarato. Trabalho docente: uma análise da produção do GT de Trabalho e Educação da ANPEd. 136 f. Dissertação (Mestrado em Educação). Centro de Educação. Universidade Federal de Santa Maria. Santa Maria, PR. 2009.

SILVA JÚNIOR, J.R et al. Trabalho do professor diante da expansão da pósgraduação em educação: o caso da região Sudeste. Relatório Científico Final. São Carlos, SP: FAPESP, Universidade Federal de São Carlos, Grupo de Economia Política da Educação, Estética e Formação Humana (GEPEFH), Abril, 2014. 


\section{Trabalhonecessário}

Issn: 1808 - 799X

ano 14, número $23-2016$

SILVA JÚNIOR, João dos Reis et al. Os significados do trabalho do professor pesquisador na Universidade estatal pública Mercantilizada. Relatório Científico Final [Processo FAPESP n. 2009/08661-0]. São Paulo: FAPESP, set. 2011.

SILVA JÚNIOR, João dos Reis. Trabalho do Professor nas Federais: estranhamento e significados. Tese de Livre Docência. Faculdade de Educação. Universidade de São Paulo, nov.2011.

SILVA, Solonildo Almeida. O caminho lato sensu da precarização do trabalho docente universitário na UECE. 90f. Dissertação (Mestrado em Educação: Políticas Públicas Educacionais). Centro de Estudos Sociais Aplicados, da Universidade Estadual do Ceará, Fortaleza, 2005.

UNIVERSIDADE FEDERAL DE SÃO CARLOS. Relatório da Gestão 2008-2012: excelência acadêmica com compromisso social. São Carlos: UFSCar, 2013.

UNIVERSIDADE FEDERAL DE SÃO CARLOS. UFSCar implanta programa de apoio ao docente recém-doutor. Informativo UFSCar. 22/03 a 28/03, 2004, p.1-2.

VICENTINI, Adriana Alves. O trabalho coletivo docente: contribuições para o desenvolvimento profissional dos professores. 166 f. Dissertação (Mestrado em Educação). Faculdade de Educação. Universidade Estadual de Campinas UNICAMP. Campinas, SP, 2006. 